\title{
AMENDMENTS
}

\section{Author Correction: Under the same sky with Amanar}

Sandra Benítez Herrera (1) and Jorge Rivero González

Correction to: Nature Astronomy https://doi.org/10.1038/s41550-020-1053-z, published online 5 March 2020.

In the version of this Comment originally published, the following text should have been included at the beginning of the Acknowledgements: 'This Comment was written on behalf of GalileoMobile, whose members are S. Benítez Herrera, F. Carrelli, A. Fernández Barral, I. Jiménez Montalvo, H. Mansour, S. Massalkhi, A. Negrín Reboso, E. Penteado, J. Rivero Gonzalez, D. Rodrigues, A. Rodriguez Antón, N. Rodriguez Eugenio, F. del Sordo, D. Torres Machado, F. Fragkoudi, A. Paula Germano, N. Gomes, P. Kobel, E. Ntormousi, M. Seidel, P. Figueiró Spinelli and M. Vasquez.' Also, the text 'Cherenkov Telescope Array network' in the 'Amanar outcomes' section and Acknowledgements was incorrect; it should have read 'Cherenkov Telescope Array Observatory'. This has now been corrected.

Published online: 23 March 2020

https://doi.org/10.1038/s41550-020-1078-3

๑) Springer Nature Limited 2020 